\title{
Altered Fire Regimes and the Persistence of Quaking Aspen in the Rocky Mountains: A Literature Review
}

\author{
Aaron Rosenblum \\ Colorado State University, Fort Collins, USA \\ Email: aaronw.rosenblum@gmail.com
}

Received 17 January 2015; accepted 19 July 2015; published 22 July 2015

Copyright (C) 2015 by author and Scientific Research Publishing Inc.

This work is licensed under the Creative Commons Attribution International License (CC BY). http://creativecommons.org/licenses/by/4.0/

(c) (i) Open Access

\begin{abstract}
The persistence of quaking aspen (Populus tremuloides Michx.) is of significant importance to land managers in the Rocky Mountain region. Fire suppression in the past century has been implicated as a mechanism influencing aspen population dynamics, as aspen are generally considered an early seral disturbance adapted species. The heterogeneity of aspen community assemblages and fire regimes makes it difficult to discern what the result of fire suppression has been at large spatial and temporal scales. Decision makers should investigate the questions at hand at the stand level in their study location to best determine the mechanisms at play, as well as consider future potential changes to the system.
\end{abstract}

\section{Keywords}

Quaking Aspen, Populus Tremuloides, Fire, Fire Regimes, Rocky Mountains

\section{Introduction}

It is well documented in a variety of ecosystems worldwide that anthropogenic influences have been causing changes in vegetation community assemblages and dynamics. In the Rocky Mountains of the western United States, apparent decline of quaking aspen (Populus tremuloides Michx.) has been a topic of significant importance and debate to scientists and land managers for multiple reasons. Aspen communities are important to biodiversity and ecosystem function and services, as well as being economically and aesthetically valuable (Bartos, 2001; Romme et al., 2001). Furthermore, quaking aspen is the most widely distributed tree species in North America and the most widespread deciduous tree species in the Rocky Mountains (Little, 1971). Recent literature is inconclusive in its findings pertaining to the stability of aspen populations in the Rocky Mountains with 
conclusions ranging from declining to persistent to increasing. Fire suppression in the Rocky Mountains beginning in the late 1880's has been implicated by many studies as a possible cause of aspen decline. This is due to the ecology of aspen as it relates to fire disturbance. This paper will review the literature and describe the current knowledge of different aspen community types, fire regimes and regeneration methods. It will also attempt to reconcile divergent findings and make recommendations for management and future areas of study.

\section{Aspen Ecology and Fire Disturbance}

Aspen trees have evolved an important life history mechanism, known as suckering, that makes them well adapted to fire disturbances. Suckering is the process of aspen clones regenerating via vegetative resprouting from lateral roots to produce new trees (Shinneman et al., 2013; Kulakowski et al., 2013). These new shoots sprout before conifer seeds have a chance to germinate giving them a competitive advantage. Suckering then leads to the dominance of aspen after a stand-replacing fire in some habitats (Kurzel et al., 2007). It is therefore no surprise that many have attributed fire suppression in the Rocky Mountains to apparent aspen decline.

\section{Heterogeneous Dynamics among Aspen Stands}

\subsection{Aspen Community Assemblage Types}

Throughout the Rocky Mountains aspen are represented in a variety of elevational gradients and community types. For example, aspens are commonly found on mountain slopes, high plateaus, mesa tops, talus slopes, avalanche chutes, low-elevation valley sides, and along riparian zones (Shinneman et al., 2013). In a coarse scale division, these habitats can be grouped into low-, mid- and high-elevational bins. Aspens at low elevations, typically 1600 - $2000 \mathrm{~m}$, occur in ponderosa pine (Pinus ponderosa) dominated forests that are historically characterized by low-severity, high-frequency surface fires (Veblen, 2000). In mid-elevation forests (2000 - 2800 $\mathrm{m}$ ), aspen coexist with ponderosa pine, Douglas-fir (Pseudotsuga menzeisii), and lodgepole pine (Pinus contor$t a$ ), and arecharacterized by mixed severity and frequency fire regimes (ibid). At high elevations (2800 - 3350), lodgepole pine, Engelman spruce (Picea engelmanni) and subalpine fir (Abies lasiocarpa) are the dominate conifer species in communities containing aspen and are characterized by infrequent, stand-replacing fires (ibid). Of course this is a highly oversimplified scheme. Several different community assemblage patterns exist within each of these three elevational gradients.

Eight community stand types within the Arapaho-Roosevelt National Forest in the Front Range of the Rocky Mountains were described by Kashian et al. (2007) to better define aspen dynamics: low-elevation aspen stands, low-elevation self-replacing aspen stands, low-elevation aspen stands mixed with ponderosa pine, low- to midelevation aspen stands seral to mixed conifers, low- to mid-elevation self-replacing aspen stands on silty soils, high-elevation aspen stands seral to Engelmann spruce and subalpine fir, high-elevation aspen stands located on steep rocky slopes, high-elevation aspen stands seral to lodgepole pine. Elevation, conifer regeneration density, density of aspen suckers, percentage of mature trees with bark browse, and percentage of aspen suckers with browse were all quantified characteristics that were highly significantly different among stand types (Kashian et al., 2007). These results illustrate the wide diversity of aspen habitats in just a single forest. Throughout the Rocky Mountains it is likely that many more community types exist.

\subsection{Seral Aspen and Succession}

As noted previously, aspen are generally regarded as an early successional species replaced through time by conifers. Once the aspen sere has reached maturity, conditions are suitable for shade-tolerant conifer species to germinate and establish in the understory. As the conifer species mature, interspecific competition increases between the tree species. Aspens in mixed conifer forests still regenerate through suckering but do not mature to reach canopy heights, whereas conifer seedlings do (Kashian et al., 2007, Smith, A. E., \& Smith, F. W., 2005). Kashian et al. (2007) reported evidence of heavy browsing by ungulates of aspen seedlings in some areas of their study and proposed it as a mechanism driving composition changes through time. However, Kurzel et al. (2007) concluded that herbivory "did not seem to be correlated with deterioration of aspen stands". With the lack of herbivory, aspen seedlings may experience reduced vigor and competitive edge in the understory of mature trees. Regardless of the driving mechanism, the observed pattern is a shift towards conifer dominance through time. Several studies (Smith, A. E., \& Smith, F. W., 2005; Kashian et al., 2007; Kurzel et al., 2007; Ku- 
lakowski et al., 2013; Shinneman et al., 2013) have noted the importance of fire to promote aspen dominance in these systems.

\subsection{Regimes of Aspen and Fire}

Due to the extreme heterogeneity of aspen habitat and community assemblage types, it should come as no surprise that aspen is affected by fire differently throughout its range. These resulting effects of fire on aspen stands are dependent on a multitude of things including fire severity, community composition and climate trends. Shinneman et al. (2013) created a fire regime classification for aspen stands naming five different relationship types:

1) Fire-independent, stable aspen stands rarely experience fire significantly into their stands because they are located within hydrologic or edaphic niches or topographically isolated sites. Aspen stands in this regime contain multiple ages of cohorts indicating regeneration independent from fire; 2) Fire-influenced, stable aspen do burn occasionally but are not dependent on fire for persistence. Fires are mixed-severity or occasionally crown replacing if the right conditions are present resulting in either mixed aged cohorts or even aged cohorts; 3) Firedependent, seral, conifer-aspen mix regime types are typically dominated by conifers. Patchy aspen regeneration is the result of frequent low- to mixed-severity fires; 4) Fire-dependent, seral, montane aspen-conifer regimes are relatively frequent mixed- to high-severity fires at mid-elevations that kill conifer species and promote aspen suckering, thus promoting aspen persistence; 5) Fire-dependent, seral, subalpine aspen-conifer regimes occur at high altitudes that experience low-frequency high-severity fires. The result is aspen stands that are seral to conifers over time.

It is also postulated by Romme et al. (2001) and Shinneman et al. (2013) that either frequent or high severity fires can destroy conifer seeds in the soil. This allows aspen communities to persist for long periods of time.

\subsection{Persistent Aspen without Fire}

There are many cases in which aspen stands persist over long periods of time in the absence of fire. In fact, Kulakowki et al. (2004) reported an increase of aspen at the landscape level in the Grand Mesa region of Colorado in present day after over 100 years of fire suppression. One theory for the episodic regeneration of aspen in the absence of fire purposed by Kurzel et al. (2007) is the Cohort Senescence Hypothesis. Originally articulated by Mueller-Dombois (1992) the theory "suggests that forests with low species diversity, predominantly even-aged stands of genetically similar trees, and distinct life spans tend to undergo periods of widespread dieback.” This widespread dieback would create excellent conditions for regeneration through suckering of the shade intolerant aspen. In the Rocky Mountains, where aspen trees are highly susceptible to disease and other influences, such as drought or insects, aspen individuals rarely last more than 120 years before giving way to younger cohorts (Kurzel et al., 2007). In addition to episodic regeneration, Kurzel et al. (2007) also recognize gap dynamics, where treefalls create small openings in the canopy, and continuous regeneration, where no new canopy opening is required, as modes of aspen regeneration. These mechanisms explain how aspen are able to regenerate and persist in the absence of fire.

\section{Discussion}

\subsection{The Importance of Scale}

Selecting the correct spatial scale to conduct investigations into the dynamics of quaking aspen and fire is very important. The interpretation of aspen dynamics at broadspatial scales can be beneficial when considering coarse scale factors such as climate or elevation. For example, the grouping of aspen stands into low-, mid- or high elevations would be wise as fire regimes, and hence aspen regenerative processes, will be highly variable between groups but somewhat similar within groups. Similarly, comparisons of aspen trends between the Rocky Mountains and the Sierra Nevada Mountains will need to be conducted at coarse spatial scales. However, broad landscape levels of examination will not detect variations in topography, soil moisture content, insect and fungal infection, etc. that are important factors in aspen dynamics. For example, Kulakowski et al. (2004) conducted a broad scale study of the Grand Mesa area in Colorado using current and historic maps and concluded that overall aspen cover has increased in the 20th century. However, it's possible that several stands within the area are actually on the decline. It may be that some mechanism is at work degrading small aspen stands while larger 
stands grow in size. This would lead to a decrease in landscape heterogeneity and likely biodiversity, which is generally seen as a negative outcome from a management standpoint. Without investigation at fine scales, the details of the change occuring and the mechanisms driving the change cannot be known. Kaye et al. (2003) support this notion stating that, "even over fairly short distances, the population structure of aspen in Colorado has been shown to be highly variable.” In summary, it is not feasible to make broad scale generalizations like, "aspen abundance is declining in the Rocky Mountains” at fine spatial scales of investigation, but at broad spatial scales mechanisms of change will often be missed.

Temporal variation of aspen dynamics and fire regimes are also of important consideration. Generally, highelevation aspen stands are said to be declining in cases where they are being successionally replaced by conifer species. However, fire regimes at this elevation are described as infrequent and high severity. Thus, the gradual replacement of aspen by conifers is natural over the course of the fire interval. However, on longer temporal scales, aspen are likely persistent on these landscapes independent of fire suppression in the last 100 years. A large stand replacing fire will still occur allowing prolific aspen regeneration and the start of a new cycle. Kashian et al. (2007) experimentally demonstrated the ability of aspen to persist in the understory of lodgepole pine dominated forests concluding, "Current densities of aspen suckers within these clearcuts suggest that aspen regenerated as vigorously after approximately 220 years of suppression as they did after approximately 80 years of suppression.” It is likely that many have come to the conclusion that aspen stands are declining because they are not considering a long enough temporal scale.

\subsection{Future Areas of Study and Implications}

The relationship between aspen dynamics and fire regimes is still not fully understood. Shinneman et al. (2013) have provided a good base with their classification scheme of fire and aspen dynamics, however, the scheme is purely qualitative. A quantitative classification scheme backed with data would give substantial benefit to future studies and the unification of hypotheses and conclusions. A potential hindrance to this achievement is the lack of methodologies that accurately date historic fire in aspen stands, as stated by Shinneman et al. (2013), "New techniques are needed to provide more robust interpretations of stand age structures and estimates of fire rotation, to reduce speculative assumptions about fire regimes caused by a lack of obvious fire evidence.” A better understanding of the relationship between aspen and fire will yield more insight into the effects of fire suppression.

Future studies need to examine a broader array of factors that affect aspen population dynamics. Of particular importance should be the effects of herbivory, climactic variation, insects, fungus, soil moisture, aspect and interspecific competition. Furthermore, the synergistic nature of these factors as well as fire should be investigated because it is highly likely that when compounded different outcomes will occur. To date, many of the studies on this topic have been observational. Future studies should use field experimental methods to provide more robust data and concrete conclusions of how these factors alter aspen population dynamics. An area of particular importance for field manipulative experimentation is climate change. While the exact effects of climate change cannot be known for certain, the fact that they will come is now inevitable. Aspen stands on the edge of their niche requirements will likely feel the hardships of climate change, especially if drought is involved.

\subsection{Management}

It is not possible to prescribe a universal management approach to aspen in the Rocky Mountains due to the extreme variability in aspen community assemblages and habitats. Land managers should approach questions at the stand level to best determine the mechanisms at play in the particular stand of interest. Broad scale generalizations should be avoided as should applying the findings of research in one region to a different one. However, the conclusions of previous studies will provide a good starting point for managers to develop questions and hypotheses. Additionally, managers should consider future potential not just historic conditions, especially if stands exist on the fringe of niche requirements.

\section{Conclusion}

There is not sufficient evidence to draw conclusions on the decline of quaking aspen populations resulting from fire suppression. This is largely due to the high degree of heterogeneity of aspen habitat and fire regimes. Many 
questions will likely be answered in the future as the question of aspen persistence will remain important to managers and researchers alike. However, currently it is clear that much research remains to be done to obtain a clear picture of long-term aspen trends in the Rocky Mountains.

\section{Acknowledgements}

A special thanks to Olivia R. Schilling for her comments and insights on an earlier version of this manuscript.

\section{References}

Bartos, D. L. (2001). Landscape Dynamics of Aspen and Conifer Forests. In: W. D., Shepperd, D., Binkley, D. L., Bartos, T. J., Stohlgren, \& L. G. Eskew (Eds.), Sustaining Aspen in Western Landscapes: Symposium Proceedings (pp. 5-14). U.S. Dep. Agric. For. Ser. Rocky Mt. For. and Range Exp. Stn. RMRS-P-18.

Kashian, D. M., Romme, W. H., \& Regan, C. M. (2007). Reconciling Divergent Interpretations of Quaking Aspen Decline on the Northern Colorado Front Range. Ecological Applications, 17, 1296-1311. http://dx.doi.org/10.1890/06-1431.1

Kaye, M. W., Stohlgren, T. J., \& Binkley, D. (2003). Aspen Structure and Variability in Rocky Mountain National Park, Colorado, USA. Landscape Ecology, 18, 591-603. http://dx.doi.org/10.1023/A:1026065826336

Kulakowski, D. et al. (2004). The Persistence of Quaking Aspen (Populus tremuloides) in the Grand Mesa area, Colorado. Ecological Applications, 14, 1603-1614. http://dx.doi.org/10.1890/03-5160

Kulakowski, D. et al. (2013). Long-Term Aspen Cover Change in the Western US. Forest Ecology and Management, 299, 52-59. http://dx.doi.org/10.1016/j.foreco.2013.01.004

Kurzel, B. P., Veblen, T. T., \& Kulakowski, D. (2007). A Typology of Stand Structure and Dynamics of Quaking Aspen in Northwestern Colorado. Forest Ecology and Management, 252, 176-190. http://dx.doi.org/10.1016/j.foreco.2007.06.027

Little Jr., E. L., (1971). Atlas of United States trees. Conifers and Important Hardwoods. Vol. 1. Misc. pub. 1146, Washington DC: US Department of Agriculture.

Mueller-Dombois, D. (1992). A Global Perspective on Forest Decline. Environmental Toxicology and Chemistry, 11, 10691076. http://dx.doi.org/10.1002/etc.5620110804

Romme, W. H. et al. (2001). Landscape Dynamics of Aspen and Conifer Forests. In: W. D., Shepperd, D., Binkley, D. L., Bartos, T. J., Stohlgren, \& L. G. Eskew (Eds.), Sustaining Aspen in Western Landscapes: Symposium Proceedings (pp. 243-259). U.S. Dep. Agric. For. Ser. Rocky Mt. For. and Range Exp. Stn. RMRS-P-18.

Shinneman, D. J. et al. (2013). Fire Regimes of Quaking Aspen in the Mountain West. Forest Ecology and Management, 299, 22-34. http://dx.doi.org/10.1016/j.foreco.2012.11.032

Smith, A. E., \& Smith, F. W. (2005). Twenty-Year Change in Aspen Dominance in Pure Aspen and Mixed Aspen/Conifer Stands on the Uncompahgre Plateau, Colorado, USA. Forest Ecology and Management, 213, 338-348.

http://dx.doi.org/10.1016/j.foreco.2005.03.018

Veblen, T. T. (2000). Disturbance Patterns in Southern Rocky Mountain Forests. In: R. L. Knight, F. W. Smith, S. W. Buskirk, W. H. Romme, \& W. L. Baker (Eds.), Forest Fragmentation in the Southern Rocky Mountains (pp. 31-54). Boulder, CO: University Press of Colorado. 